\title{
Copper Poisoning in Farm Animals: Diagnostic and Preventive Approaches
}

\author{
S. K. Jaiswal ${ }^{1 *}$, R. K. Gupta ${ }^{1}$, Sonu Jaiswal ${ }^{2}$ and D. Niyogi ${ }^{1}$ \\ ${ }^{1}$ Department of Veterinary Pathology, ${ }^{2}$ Department of Veterinary Clinical Complex, C.V.Sc \& \\ A.H, ANDUAT, Kumarganj, Ayodhya, Uttar Pradesh-224229, India \\ *Corresponding author
}

\section{A B S T R A C T}

Keywords

Copper, haemolysis, haemoglobinuria, poisoning, diagnosis, prevention

Article Info

Accepted:

22 December 2019

Available Online:

20 January 2020
This review article represents copper poisoning in farm animals with special emphasis on pathogenesis, clinical findings, diagnostic and preventive approaches. Diagnosis of any poisoning is very difficult and can't be based on any single observation. keeping in view regarding difficulties in diagnosis, it must be combination of history, clinical signs, pathological findings, tests results, response to therapy and most important, the judgement of a toxicologist. Copper is an integral part of many important enzymes involved in number of vital biological processes like metalloprotein enzymes, metalloporphyrin enzymes. Copper is required, but is also highly toxic. Most of the cases of poisoning remain undiagnosed because of the lack of sophisticated techniques at veterinary hospitals.

\section{Introduction}

Animlas are exposed accidentally or maliciously to various toxic chemicals including copper. Copper is an integral part of many important enzymes involved in number of vital biological processes like metalloprotein enzymes, metalloporphyrin enzymes (Gaetke et al., 2003). Acute or chronic copper poisoning is encountered in most parts of the world. Sheep are affected most often, although other species are also susceptible. Acute poisoning is usually seen after accidental administration of excessive amounts of soluble copper salts, which may be present in anthelmintic drenches, mineral mixes, or improperly formulated rations. Many factors that alter copper metabolism influence copper poisoning by enhancing the absorption or retention of copper. Low levels of molybdenum or sulphate in the diet are important examples. Primary chronic poisoning is seen most commonly in sheep when excessive amounts of copper are ingested over a prolonged period. Phytogenous and hepatogenous factors 
influence secondary chronic copper poisoning. Incidence has increased in recent years with the intensification of the sheep industry, increased housing of ewes, increased use of breeds susceptible to copper poisoning, such as the Texel. A very high concentration of copper produce genotoxicity and cytotoxicity in bovine cumulus cells (Anchordoquy et al., 2017).

\section{Sources}

Acute poisoning may follow intakes of 20$100 \mathrm{mg}$ of copper/kg in sheep and young calves and of $200-800 \mathrm{mg} / \mathrm{kg}$ in mature cattle. Chronic poisoning of sheep may occur with daily intakes of $3.5 \mathrm{mg}$ of copper $/ \mathrm{kg}$ when grazing pastures that contain 15-20 ppm (dry matter) of copper and low levels of molybdenum. Clinical disease may occur in sheep that ingest cattle rations, which normally contain higher levels of copper or when their water is supplied via copper plumbing. Phytogenous and hepatogenous factors influence secondary chronic copper poisoning. Phytogenous chronic poisoning is seen after ingestion of plants, such as subterranean clover (Trifolium subterraneum), that produce a mineral imbalance and result in excessive copper retention. The plants that are not hepatotoxic contain normal amounts of copper and low levels of molybdenum. The ingestion of plants such as Heliotropium europaeumor and Senecio spp for several months may cause hepatogenous chronic copper poisoning. These plants contain hepatotoxic alkaloids, which result in retention of excessive copper in the liver. In cattle, occasionally, copper poisoning has been associated with cattle eating pig feed or grazing pastures fertilised with pig manure. Copper containing pesticides and fungicides in orchards where animal graze, industrial copper waste in rivers and streams, slurry spreading from pig units are also important source (Kerr and McGavin, 1991).

\section{Susceptibility}

Both sexes of sheep are susceptible to copper toxicity. Young animals are more susceptible to the toxicity. However, mature British breed ewes are the most susceptible. These breeds include Suffolks, Oxfords and Shropshires. Texels from Netherland are the most susceptible. Finnsheep are the least likely to develop a copper toxicity. Merino sheep have an intermediate occurance of copper toxicity. Sheep tend to be much more sensitive than other farm animals. For example, growing swine are often fed copper concentrations as high as $250 \mathrm{ppm}$ in the diet to improve performance. Cattle can consume diets containing 100 ppm copper with no problem, while toxicities have occurred in sheep with concentrations as low as $10 \mathrm{ppm}$. This all is due to liver of the sheep stores copper extremely efficiently. Once the buildup reaches a certain threshold, the copper may spill into the bloodstream. This threshold is about 1,000 to 3,000 parts per million. The spilling of the copper into the bloodstream causes hemolytic crisis.

Chronic toxicity is also common in sheep grazing subterranean clover and is associated with normal levels of copper, low levels of molybdenum and no apparent liver damage. The stress associated with shipping ewes from mountain ranges to pastures some distance away appears to make ewes more susceptible. Subclinical toxicity has been recorded in Suffolk and Texel-cross lambs fed diets containing $0.19 \mathrm{mmol}(12 \mathrm{mg}) \mathrm{Cu} / \mathrm{kg} \mathrm{DM}$, a level often exceeded in commercial foodstuffs (Woolliams et al.,1982).

\section{Pathogenesis}

Oral intake of copper lead to necrosis of GIT mucosa (acute toxicity), then it is absorbed and comes to systemic circulation and enters the RBCs which become more fragile leading to haemolysis because of decreased 
glutathione concentration in $\mathrm{RBC}$ as cupric ions interact with sulphur group of glutathione. In $\mathrm{RBC}$ ferrous ions is replaced by cupric ions and formation of methaemoglobin take place which ultimately leads to haemolytic crisis. Storage mainly occur in liver but to threshold level. High concentration of copper inhibit various metabolic function and causes liver necrosis. The toxicosis remains subclinical until the copper that is stored in the liver is released in massive amounts. Increased liver enzymes may provide an early warning of the pending crisis. Blood copper concentrations increase suddenly, causing lipid peroxidation and intravascular haemolysis. The haemolytic crisis may be precipitated by many factors, including transportation, handling, weather conditions, pregnancy, lactation, strenuous exercise, or a deteriorating plane of nutrition. The sudden onset of clinical signs in chronic copper poisoning is associated with the haemolytic crisis. The time of onset is influenced by the concentration of copper in the diet. This lead to increased SGOT and CPK level. Increased CPK level damages skeletol muscles. Haemoglobinuria occurs as a result of haemolysis.

\section{Clinical findings}

Acute copper poisoning causes severe gastroenteritis characterized by abdominal pain, diarrohea, anorexia, faeces contain mucous with deep greenish appearance, dehydration, and shock. Haemolysis and haemoglobinuria may develop after 3 days if the animal survives the GI disturbances. Chronic copper poisoning is more likely to occur with excessive copper intakes or from low intakes of molybdenum, sulphur, zinc, calcium or following liver damage (Kimberling, 1988).Signs in affected animals include depression, lethargy, weakness, rumen stasis, yellowishc conjunctiva (Fig. 1), anorexia, thirst, dyspnea, pale mucous membranes, recumbency, hemoglobinuria, and jaundice. Several days or weeks before the haemolytic crisis, liver enzymes, including ALT and AST, are usually increased. During the haemolytic crisis, methemoglobinemia, hemoglobinaemia, and decreases in PCV and blood glutathione are usually seen. Morbid animals often die within 1-2 days. Herd morbidity is often $<5 \%$, although usually $>75 \%$ of affected animals die. Severe hepatic insufficiency is responsible for early deaths. Animals that survive the acute episode may die of subsequent renal failure. Photosensitization may occur in association with chronic copper poisoning, reflecting the hepatotoxicity common to both syndromes.

\section{Lesions}

Acute copper poisoning produces severe gastroenteritis with erosions and ulcerations in the abomasum of ruminants. Icterus develops in animals that survive greater than $24 \mathrm{hr}$. Tissues discoloured by icterus and methaemoglobin are characteristic of chronic poisoning. Swollen, gunmetal-coloured (Fig.2) kidneys (characteristics of copper poisoning), port-wine-coloured urine and an enlarged spleen with dark brown-black parenchyma (blackberry jam appearance) are result of the haemolytic crisis (Garg, 2002). The liver is enlarged and friable. Histologically, there is centrilobular hepatic and renal tubular necrosis. Brain may show spongy degeneration and astrocyte damage (Haywood et al., 2008).

\section{Diagnosis}

Diagnosis of any poisoning is very difficult and cannot be based on any single observation. keeping in view regarding difficulties in diagnosis, it must be combination of history, clinical signs, postmortem findings, tests results, response to therapy and most important, the judgement of toxicologist. Diagnosis of copper poisoning is made on the basis of history, clinical signs, 
post-mortem findings and laboratory examination. After post-mortem examination, the carcass suspected for copper poisoning, liver, kidney, blood, faeces and urine must be collected. Evidence of blue-green ingesta, deep green coloured faeces and increased faecal (8,000-10,000 ppm) and kidney (>15 ppm, wet weight) copper levels are considered significant in acute copper poisoning. In chronic poisoning, blood and liver copper concentrations are increased during the haemolytic period. Blood concentrations often rise to $5-20 \mathrm{mcg} / \mathrm{mL}$, as compared with normal levels of $1 \mathrm{mcg} / \mathrm{mL}$. Liver concentrations $>150 \mathrm{ppm}$ (wet weight) are significant in sheep (Garg, 2002). The concentration of copper in the tissue must be determined to eliminate other causes of haemolytic disease. Molybdenum tissue concentrations should be evaluated to determine whether the syndrome is due to primary or secondary chronic copper poisoning.

\section{Treatment and control}

Although prevention is much preferred, there are times when mass treatment is indicated. The most common treatment is to give a drench daily containing 50 to $100 \mathrm{mg}$ of ammonium molybdate and 0.5 to $1.0 \mathrm{~g}$ of sodium sulphate per animal for three weeks. To reduce labour, an aqueous solution of the two salts can be sprayed onto the feed. This approach is recommended as a treatment procedure only if all animals are eating regularly.

GI sedatives and symptomatic treatment for shock may be useful in acute toxicity. Penicillamine $(50 \mathrm{mg} / \mathrm{kg} /$ day, $\mathrm{PO}$, for 6 days) or calcium versenate may be useful if administered in the early stages of disease to enhance copper excretion. Vitamin C (500 $\mathrm{mg} /$ day/sheep, SC) has been shown to reduce oxidative damage to RBCs during the haemolytic crisis. Ammonium tetrathiomolybdate $(1.7 \mathrm{mg} / \mathrm{kg}$, IV, every other day for 6 days) is effective. This treatment, which reduces copper absorption and enhances copper elimination, should be used conservatively. A withdrawal period of 10 days is required for this medication. Daily oral administration of ammonium molybdate (100 $\mathrm{mg}$ ) and sodium thiosulfate (1 g) for 3 week reduces losses in affected lambs. Dietary supplementation with zinc acetate $(250 \mathrm{ppm})$ may be useful to reduce the absorption of copper. Plant eradication or reducing access to plants that cause phytogenous or hepatogenous copper poisoning is desirable.

Primary chronic or phytogenous poisoning may be prevented by top-dressing pastures with $30 \mathrm{ml}$ of molybdenum per acre in the form of molybdenized superphosphate or by molybdenum supplementation or restriction of copper intake.

A combination therapy of tetrathiomolybdate and d-penicillamine(degradation product $\mathrm{f}$ penicillin that chelates copper) has also been identified as being useful to maximize copper removal from the body (Gooneratne and Christiansen, 1997). Fresh seaweed offered to sheep with symptoms of copper toxicity appeared to be therapeutic, leading to a reduction in blood plasma copper level (Wiener et al., 1977). Sodium molybdate at rate of $200 \mathrm{mg}$ per day can markedtly reduce liver copper stores within 4 weeks in dairy cows (Morgan et al., 2014). High-risk flocks of sheep may be supplemented with sodium thiosulfate in the diet to prevent or control chronic copper poisoning. Periodic liver biopsies, tissue copper determination, and liver enzyme assessment may also be useful to evaluate disease status. In addition to previously described treatments, zinc supplementation and prednisone or prednisolone administration enhance copper excretion and limit development of liver disease. 
Fig.1 Yellowish conjunctivae in cattle

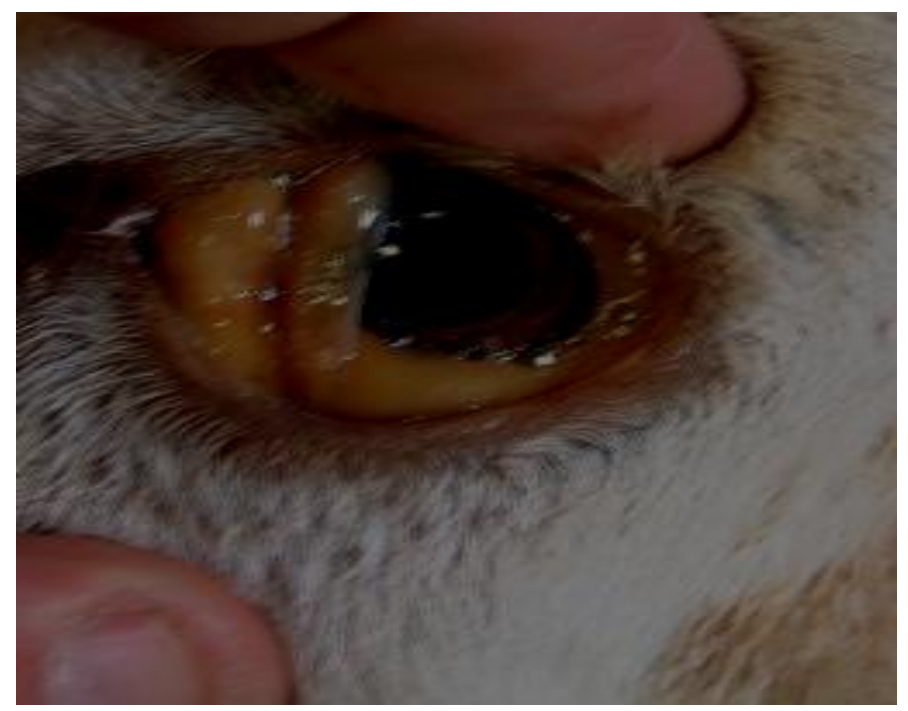

Fig.2 Gnn metal kidney

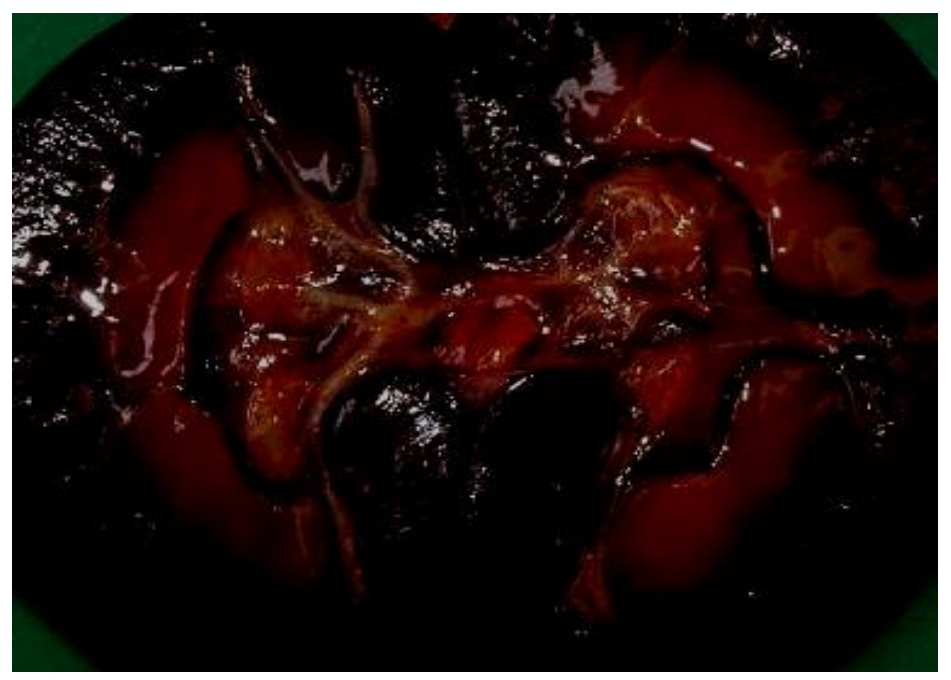

\section{Prevention}

Do not supplement with copper unless you have clear evidence of copper deficiency (or molybdenum toxicity).

When supplementing sheep with copper, make sure only one source of copper is available and avoid stress during copper treatment and for a period afterwards.
Anthelmintics and any period of food deprivation around the time of copper treatment should be avoided.

Do not feed excessive levels of concentrate to sheep.

Do not feed concentrates high in copper levels to sheep, especially to sheep breeds susceptible to copper poisoning and housed sheep. 
Do not feed sheep food compounded for other species.

Do not use copper sulphate for the control of snails in areas where sheep are grazing. Ensuring you know what the copper intake of your cows. Pay particular attention to the copper content of your mineral and your forage.

Copper is regularly used in the diet at about 811 parts per million. It may be toxic to sheep at $15-20$ parts per million. There is a narrow difference between the amount of copper required and what will be toxic to the animal. A diet should never have copper level above 25 parts per million to be safe for most sheep.

In many parts of the country where adequate levels of copper is found in the pastures, it is not necessary to add copper to the diet. Copper toxicity may result from low levels of molybdenum, sulphur, zinc, and calcium. The most important factor is the copper to molybdenum ratio. A ratio of $10: 1$ will prevent toxicity. Some plants consumed by sheep may cause a toxicity. Lupines, a type of plant, contain toxic alkaloids that impair the liver's ability to metabolize ingested copper.

There is evidence that the incidence of copper toxicosis in sheep may be controlled by increasing their dietary zinc intake (Bremner et al., 1976).

\section{References}

Anchordoquy Juan Mateo, Anchordoquy Juan Patricio, Nikoloff Noelia, Pascua Ana M, Furnus Cecilia C. High copper concentration produce genotoxicity and cytotoxicity in bovine cumulus cells. Environmental Science and Pollution Research. 2017; 24 (24): 20041-20049.
Bremer I, Young B W and Mills C F. Protective effect of zinc supplementation against copper toxicosis in sheep. British Journal of Nutrition. 1976; 36 (03):551.

Gaetke Lisa $M$ and Chow Ching Kuang. Copper toxicity, oxidative stress and antioxidant nutrients. Toxicology. 2003; 189 (1-2): 147-163.

Garg Satish K. Veterinary Toxicolgy. Edn 1, CBS Publishers, Delhi, 2002, 53-57.

Gooneratne S R and Christensen D A. Effect of chelating agents on the excreation of copper, zinc and iron in the bile and urine of sheep. London Veterinary Journal. 1997; 153 (2):171-178.

Haywood S, Paris J, Ryvar R and Botteron. Brain copper elevation and neurological changes in north ronaldsay sheep: a model for neurodegenerative disease?. Journal of Comparative Pathology. 2008; 139(4): 252-255.

Kerr L A and McGavin H D. Chronic copper poisoning in sheep grazing pastures fertilised with swine manure. Journal of the American Medical Association. 1991; 198 (1): 99-101.

Morgan P L. Grace N D and Lilley D P. Using sodium molybdate to treat chronic toxicity in dairy cows: a practical approach. New Zealand Veterinary Journal. 2014; 62 (3): 167-170.

Wooliams J A, Suttle N F, Weiner G, Field A $\mathrm{C}$ and Wooliams $\mathrm{C}$. The effect of breed of sire on the accumulation of copper in lambs, with particular reference to copper toxicity. Animal Production. 1982; 35(03): 299-307.

Weiner G, Field A C and Smith C. Deaths from copper toxicity of sheep at pasture and the use of fresh seaweed. The Veterinary Record. 1977; 101 (21): 424-125. 


\section{How to cite this article:}

Jaiswal, S. K., R. K. Gupta, Sonu Jaiswal and Niyogi, D. 2020. Copper Poisoning in Farm Animals: Diagnostic and Preventive Approaches. Int.J.Curr.Microbiol.App.Sci. 9(01): 22242230. doi: https://doi.org/10.20546/ijcmas.2020.901.252 